\title{
A population based, prospective study of the development of ROP in prematurely born children in the Stockholm area of Sweden
}

Huddinge University
Hospital
G Holmström
M el Azazi
G Lennerstrand
Danderyds Hospital
G Holmström
M el Azazi
St Görans Hospital
G Holmström
Karolinska Hospital,
Stockholm, Sweden
L Jacobson
Correspondence to:
Dr G Holmström, Department
of Ophthalmology, Huddinge
University Hospital, S-141 86
Huddinge, Sweden.
Accepted for publication
19 February 1993

Huddinge University

Hospita

G Holmströ

G Lennerstrand

Danderyds Hospital

St Görans Hospital G Holmström

Karolinska Hospital, L Jacobson

Correspondence to: of Ophthalmoln, Department (141

Accepted for publication 19 February 1993

\author{
G Holmström, M el Azazi, L Jacobson, G Lennerstrand
}

\begin{abstract}
A prospective population based study including 260 children with a birth weight of $1500 \mathrm{~g}$ or less was performed in the Stockholm county. The total incidence of retinopathy of prematurity (ROP) was 40.4\%, while severe ROP - that is, stage 3 or more, was seen in $20.0 \%$. Cryotherapy was performed in $10.8 \%$. Logistic regression analysis revealed independent association of both gestational age and birth weight with ROP. The association of gestational age and ROP was significantly stronger, indicating that the degree of immaturity of the eye is a main predictive factor for the development of ROP. The purpose of a general screening for ROP is to identify children requiring cryotherapy. Based on these results it seems appropriate to include children with a gestational age of 32 weeks or less in such a programme and a first examination at 5-6 weeks of postnatal age is suggested.
\end{abstract}

(Br f Ophthalmol 1993; 77: 417-423)

During the past 15 years, the survival rate of very immature children as well as the frequency of retinopathy of prematurity (ROP) has increased. ${ }^{1}$ Many reports have been published on the prevalence and the development of ROP. ${ }^{1-10}$ However, the majority of them have been based on selected hospital data and to our knowledge only a few population based studies have been undertaken.

Recently an international classification of ROP has been introduced. ${ }^{11}{ }^{12}$ Prospective studies on populations from specific communities using this classification have been performed in New Zealand, ${ }^{13}$ England, ${ }^{14}$ and Denmark. ${ }^{15}$ From Canada two prospective studies ${ }^{1617}$ have been reported, but they were based on the old classification of the disease and hence, they are not really comparable with data obtained with the international classification. Retrospective, community based studies have been made in Denmark ${ }^{18}$ and recently in Sweden..$^{1920}$

A multicentre study in the United States ${ }^{21}$ has reported a favourable outcome of cryotherapy performed at a defined threshold stage of ROP. It has therefore become the responsibility of paediatric ophthalmologists to define the risk group of premature children and identify those requiring cryosurgery. However, screening is time consuming and expensive and an appropriate programme has to be designed to suit the local health care system and the needs of the population in the specific area. It also has to be based on a profound knowledge of the epidemiology of ROP in that specific area.
The purpose of this prospective study was to investigate the incidence of ROP among premature children in a well defined geographical area in Sweden. We also wanted to investigate the incidence of performed cryosurgery and other forms of surgery. The relation of ROP to factors such as birth weight, gestational age, and sex were other questions that needed to be explored in our population.

Based on the findings of this study we wanted to create a realistic screening programme of premature children in our area in order to identify those with threshold ROP requiring cryosurgery. We are also planning to follow the whole group of children up to the age of 3.5-4 years to investigate the prevalence of different visual dysfunctions, refractive errors, and strabismus and this will be reported in the future.

\section{Materials and methods}

Premature children with a birth weight of $1500 \mathrm{~g}$ or less and surviving for at least 8 weeks, born in the Stockholm county between 1 September 1988 and 31 October 1990 were included in the study. There are five different neonatal units in different hospitals in the county (Danderyds Hospital, Huddinge University Hospital, Karolinska Hospital, Sachsska Hospital, and St Görans Hospital) where all prematurely born babies are cared for and treated in a very similar way. Before the study was started the examination technique and protocol as well as the definition of different stages of ROP including 'plus disease' were very carefully discussed and agreed upon among the participating ophthalmologists. The international classification of ROP was used. ${ }^{112}$ The participating ophthalmologists, who made the eye examinations and the follow up at each neonatal unit, also performed the follow up after the child had been discharged. For determination of the gestational age ultrasonography was routinely performed on all mothers at the beginning of the pregnancy. The following terminology is used throughout the paper to describe the age and the degree of maturity of the child: Gestational age - the time from the first day of the last menstruation up to birth; postnatal age - the age in weeks after birth; and postmenstrual age - the addition of gestational age and postnatal age.

From the birth registers of the Swedish National Board of Health and Social Welfare we received data of all prematurely born children with a birth weight of $1500 \mathrm{~g}$ or less during the period of study. From these data we determined the survival rate in this group of children and also 
the number of dropouts - that is, children that were not reported to us from the neonatal units.

\section{EXCLUSION CRITERIA}

Children having their first examination later than 6 weeks of age were excluded from the study, provided the first examination was performed later than 40 weeks postmenstrual age. Children were also excluded if they had their last examination too early - that is, before the retina was fully vascularised.

\section{EXAMINATION TECHNIQUE}

The pupils were dilated with a mixture of cyclopentholate $0.2 \%$ and phenylephrine $1.0 \%$ administered twice. Indirect ophthalmoscopy was performed. A lid speculum, a scleral indentator, and topical anaesthesia were used when necessary, to rotate the eye in order to examine the periphery when this was not possible by simply using the doll's head manoeuvre. The first examination was performed between 4 and 6 weeks postnatally, the second examination 2 weeks later, and the following examination at 2 to 3 week intervals depending on the postmenstrual age of the child. The examinations were repeated until the retina was fully vascularised in the periphery. If ROP was detected, the intervals between examinations were lessened to 1 week or less, depending on the stage of the disease.

\section{CRYOTHERAPY}

In our study necessity for cryosurgery was confined to ROP stage 3 with confluent fibrovascular proliferations and 'plus disease'. If confluent proliferations of at least four clock hours in zone II were present, even in the absence of 'plus disease' (dilatation and tortuosity of the posterior retinal vessels), cryotherapy was also performed. In Stockholm all cryotherapy was centralised and performed at a specially equipped paediatric hospital (St Görans Hospital), which means that a delay in the treatment of up to 3 to 4 days may occur after the decision to use cryotherapy has been made. The cryosurgery was undertaken under general anaesthesia using a standard retinal and/or cataract probe. The avascular part of the retina anterior

Table 1 Relation of ROP to birth weight

\begin{tabular}{lcccc}
\hline \multirow{4}{*}{ Birth weight $(\mathrm{g})$} & \\
\cline { 2 - 4 } Stage of ROP & $\leq 750$ & $751-1000$ & $>1000$ & Totals \\
\hline No ROP $(\%)$ & $3(23 \cdot 1)$ & $29(47 \cdot 5)$ & $123(66 \cdot 1)$ & 155 \\
Mild ROP $(\%)$ & $3(23 \cdot 1)$ & $14(23 \cdot 0)$ & $36(19 \cdot 4)$ & 53 \\
Severe ROP $(\%)$ & $7(53 \cdot 8)$ & $18(29 \cdot 5)$ & $27(14 \cdot 5)$ & 52 \\
Totals & 13 & 61 & 186 & 260 \\
\hline
\end{tabular}

Table 2 Relation of ROP to gestational age

\begin{tabular}{llllll}
\hline & \multicolumn{3}{l}{ Gestational age (weeks) } & \\
\cline { 2 - 5 } Stage of ROP & $24-26$ & $27-29$ & $30-32$ & $33-35$ & Totals \\
\hline No ROP $(\%)$ & $10(28 \cdot 6)$ & $72(57 \cdot 6)$ & $53(68 \cdot 0)$ & $20(90 \cdot 9)$ & 155 \\
Mild ROP $(\%)$ & $9(25 \cdot 7)$ & $30(24 \cdot 0)$ & $12(15 \cdot 4)$ & $2(9 \cdot 1)$ & 53 \\
Severe ROP $(\%)$ & $16(45 \cdot 7)$ & $23(18 \cdot 4)$ & $13(16 \cdot 6)$ & $0(0)$ & 52 \\
Totals & 35 & 23 & 78 & 22 & 260 \\
\hline
\end{tabular}

to the ridge was treated transconjunctivally in a contiguous, single row. After treatment the children were followed up by their own ophthalmologists in the neonatal units or as outpatients.

The study was approved by the ethical committee of the Karolinska Institute, Stockholm, Sweden.

\section{Results}

The total study population included 295 children, born in the Stockholm county, with a birthweight of $1500 \mathrm{~g}$ or less and surviving for at least 8 weeks; 21 children were excluded from the study according to our exclusion criteria. From the birth registers of the Swedish National Board on Health and Welfare we identified another 14 children born during the study period, with a birth weight of $1500 \mathrm{~g}$ or less and surviving for at least 8 weeks, but who were not referred to us and, hence, were not examined. This gave a total dropout number of 35 of the 295 children (11.9\%). According to the birth registers, altogether 350 children with a birth weight of $1500 \mathrm{~g}$ or less were live born during the study period. During the first 7 weeks of life 55 children had died, giving a survival rate for at least 8 weeks of $84 \%$.

Two hundred and sixty children fulfilled our criteria for inclusion in the study. There were $134(51 \cdot 5 \%)$ girls and $126(48 \cdot 5 \%)$ boys: 203 children $(78 \cdot 1 \%)$ were results of single births and $57(21.9 \%)$ of multiple births. The mean gestational age was 29 weeks (range 24-35 weeks) and the mean birth weight was $1157 \mathrm{~g}$ (range 648$1500 \mathrm{~g}$ ). Examinations were made twice or more in $246(94.6 \%)$ children and five times or more in 83 children $(35 \cdot 1 \%) ; 14$ children $(5 \cdot 4 \%)$ had only one examination. The first examination was performed at 6 weeks of postnatal age or earlier in $209(80.4 \%)$ children and at 8 weeks of postnatal age or earlier in $252(96.9 \%)$ children.

ROP of any stage was seen in $105(40.4 \%)$ children: stage 1 was seen in $24(9 \cdot 2 \%)$ children; stage 2 in $29(11 \cdot 2 \%)$; stage 3 in $45(17 \cdot 3 \%)$; stage 4 in six $(2 \cdot 3 \%)$; and stage 5 in one $(0.4 \%)$ child. Altogether mild ROP, defined as stage 1 or 2 , was seen in $53(20.4 \%)$ and severe ROP, defined as stage 3 or more, was seen in $52(20.0 \%)$ children. There was a significant correlation between ROP, particularly severe ROP, and low birth weight ( $p=0.0008$, tested with $\chi^{2}$ analysis) (Table 1$)$ and early gestational age $(\mathrm{p}=0.0001$, tested with $\chi^{2}$ analysis) (Table 2, Fig 1 ). There were no significant correlations between sex or single or multiple birth and any of the ROP stages (tested with $\chi^{2}$ analysis). No significant difference between the right and the left eye at any of the ROP stages (tested with $t$ test) was found. A logistic regression analysis of the association of four different parameters to ROP was performed. Sex, gestational age at birth, birth weight, and multiple birth were used as independent parameters, but only gestational age (log coefficient $0 \cdot 29$, standard error $0 \cdot 76, \mathrm{p}$ value $<0.001$ ) and birth weight (log coefficient $0 \cdot 16$, standard error 0.72 , $p$ value $<0.05$ ) were independently associated with ROP.

Among the 57 children who were the result of multiple births, $10(17 \cdot 5 \%)$ had severe ROP (nine stage 3 and one stage 5) compared with 42 


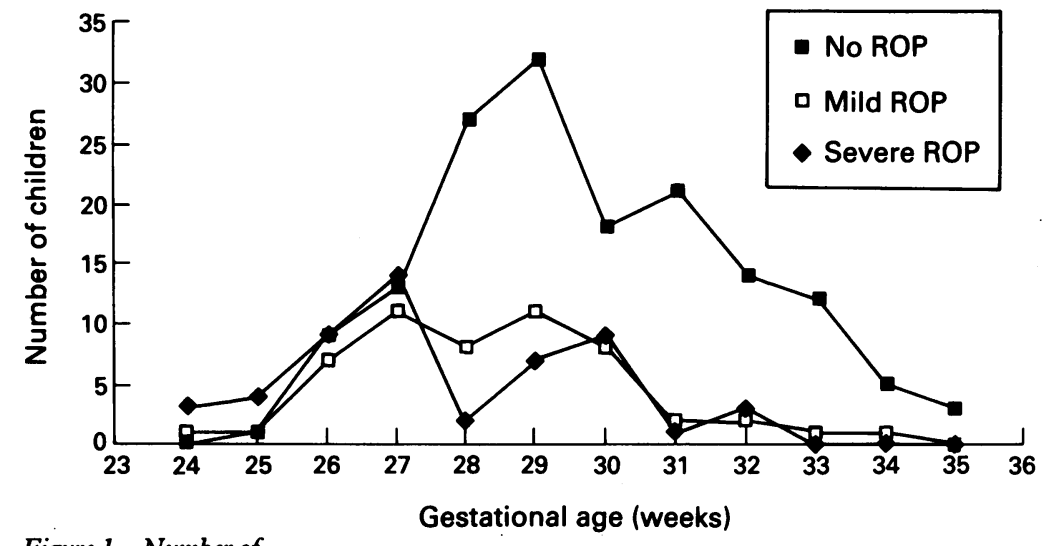

Figure 1 Number of children with no ROP, mild $R O P$, and severe ROP at different weeks of gestation.

of the $203(20 \cdot 7 \%)$ single births. There were 19 sets of twins and quadruplets fulfilling the criteria of inclusion. In eight of the sets the stage of ROP was similar, while in 11 of the sets, the sisters and brothers had different stages of ROP.

Among the 35 dropouts two children had a reported birth weight of $750-1000 \mathrm{~g}$ and 33 children a birth weight of more than $1000 \mathrm{~g}$. According to the birth weight of the dropouts we have calculated the incidence of ROP in different weight groups - that is, birth weights of $\leq 750 \mathrm{~g}$, $750-1000 \mathrm{~g}$, and $>1000 \mathrm{~g}$. The estimated incidence of ROP in the total population of 295 children was $39 \cdot 7 \%$. The estimated incidence of mild ROP was $20 \cdot 3 \%$ and of severe ROP $19 \cdot 4 \%$.

At the first examination $48(18 \cdot 5 \%)$ children already had some degree of ROP. At the onset of ROP the mean postnatal age and the mean postmenstrual age were 7.9 weeks (range 3-16) and 36 weeks (range 31-43) respectively. The age range (mean values and standard deviations) of the time of detection of different stages of ROP, both in terms of postmenstrual age and postnatal age was analysed. Since $t$ tests showed no significant difference between the right and the left eye, we have chosen to present the results of the right eyes only. The number of right eyes reaching a certain stage of ROP at some point and the number of right eyes showing some degree of ROP at the first examination are presented in Table 3. The mean values, and the standard deviations, of the onset time of different stages of ROP illustrate the progression and natural history of the disease related to postnatal and postmenstrual age (Figs 2 and 3 ). The relation of birth weight and gestational age to ROP onset at postnatal and postmenstrual age respectively, was also analysed. There was a significant inverse correlation of birth weight and onset at postnatal age (correlation coefficient 0.374 , $p$ value $<0.0001$ ) (see Fig 4A). There was also a significant reciprocal correlation of gestational age and onset at postnatal age (correlation coefficient $0.435 \mathrm{p}$ value $<0.0001$ )

Table 3 Onset of different stages of ROP (right eyes)

\begin{tabular}{lllll}
\hline $\begin{array}{l}\text { Stage } \\
\text { of ROP }\end{array}$ & $\begin{array}{l}\text { Total number } \\
\text { of right eyes }\end{array}$ & $\begin{array}{l}\text { Number of right } \\
\text { eyes with ROP at } \\
\text { first examination }\end{array}$ & $\begin{array}{l}\text { Onset time of ROP- } \\
\text { postmatal age (weeks) } \\
\text { Mean }(S D)(\text { range })\end{array}$ & $\begin{array}{l}\text { Onset time of ROP- } \\
\text { postmenstrual age (weeks) } \\
\text { Mean (SD)(range) }\end{array}$ \\
\hline 1 & 41 & 18 & $6 \cdot 9(2 \cdot 7)(3-16)$ & $35 \cdot 6(2 \cdot 5)(31-42)$ \\
2 & 58 & 18 & $8 \cdot 6(2 \cdot 4)(4-15)$ & $36 \cdot 2(2 \cdot 5)(32-44)$ \\
3 & 44 & 7 & $9 \cdot 8(3 \cdot 0)(5-18)$ & $37 \cdot 6(2 \cdot 9)(32-44)$ \\
4 & 4 & 0 & $14 \cdot 5(4 \cdot 4)(11-21)$ & $40 \cdot 5(3 \cdot 1)(38-45)$ \\
5 & 1 & 0 & 15 & 42 \\
\hline
\end{tabular}

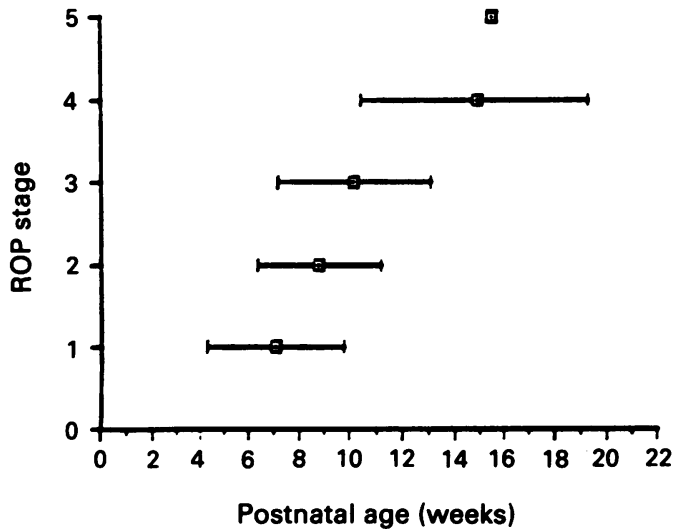

Figure 2 Onset time (mean value and standard deviation) of different $R O P$ stages in relation to postnatal age. Exact number of eyes, mean values, and standard deviations are presented in Table 3.

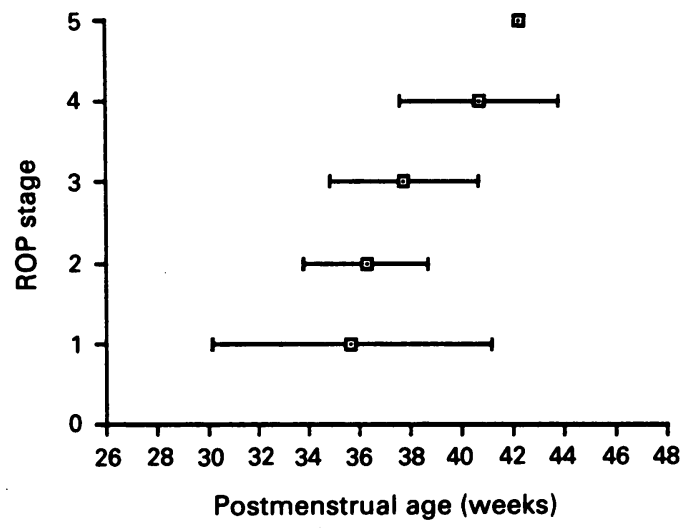

Figure 3 Onset time (mean value and standard deviation) of different $R O P$ stages in relation to postmenstrual age. Exact number of eyes, mean values, and standard deviations are presented in Table 3.
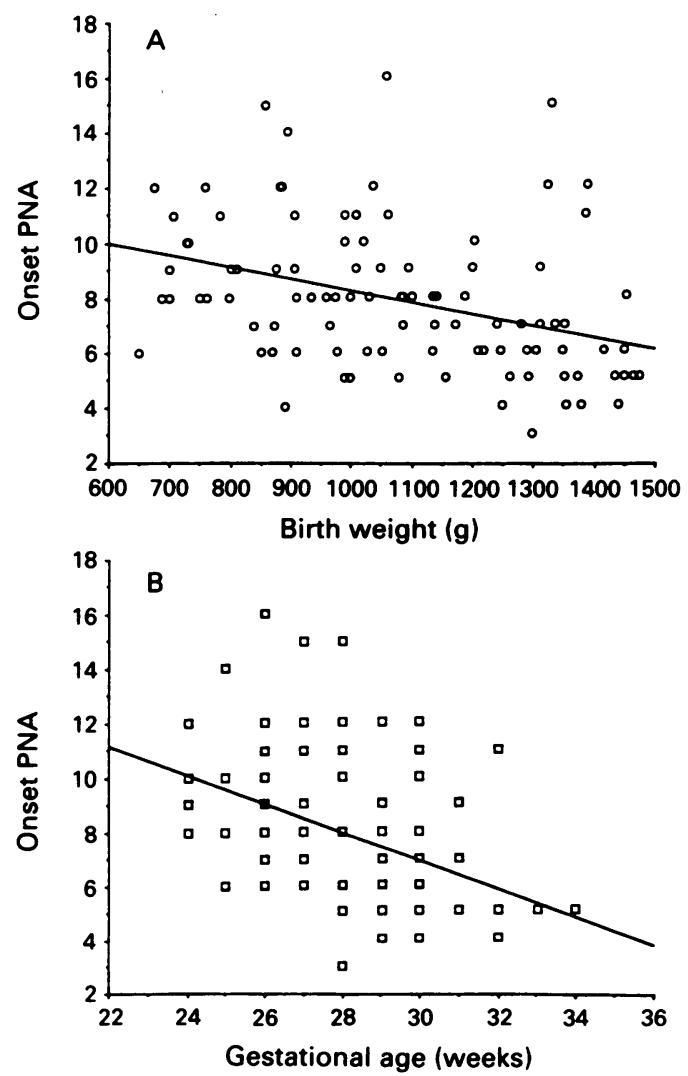

Figure 4 (A) Inverse correlation of birth weight ( $g$ ) and onse of ROP at postnatal age (PNA) in weeks (correlation coefficient $0 \cdot 374$, p value $<0 \cdot 0001$ ). (B) Inverse correlation of gestational age (weeks) and onset at postnatal age (PNA) in weeks (correlation coefficient 0.435, p value $<0.0001$ ). 

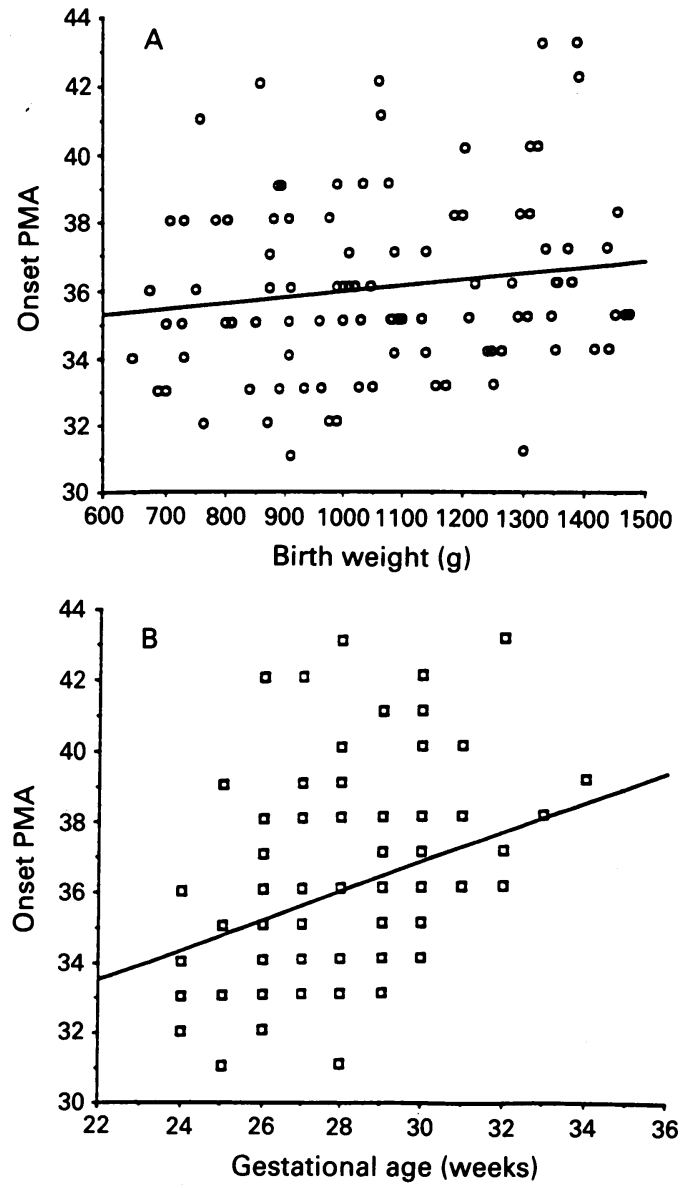

(see Fig 4B). There was no correlation of birth weight and onset at postmenstrual age (correlation coefficient $0 \cdot 12, p$ value $0 \cdot 2$ ) (see Fig $5 \mathrm{~A}$ ), while there was a significant correlation of gestational age and onset at postmenstrual age (correlation coefficient 0.329 , $\mathrm{p}$ value $<0.001$ ), (see Fig 5B).

Table 4 Relation of performed cryotherapy to birth weight

\begin{tabular}{lllll}
\hline & \multicolumn{3}{l}{ Birth weight $(\mathrm{g})$} & \\
\cline { 2 - 4 } Cryotherapy & $\leq 750$ & $751-1000$ & $>1000$ & Totals \\
\hline No $(\%)$ & $10(76 \cdot 9)$ & $45(73 \cdot 8)$ & $177(95 \cdot 2)$ & 232 \\
Yes (\%) & $3(23 \cdot 1)$ & $16(26 \cdot 2)$ & $9(4 \cdot 8)$ & 28 \\
Totals & 13 & 61 & 186 & 260 \\
\hline
\end{tabular}

Table 5 Relation of performed cryotherapy to gestational age

\begin{tabular}{llllll}
\hline \multirow{5}{*}{ Cryotherapy } & \multicolumn{4}{l}{ Gestational age (weeks) } & \\
\cline { 2 - 5 } & $24-26$ & $27-29$ & $30-32$ & $33-35$ & Totals \\
\hline No (\%) & $23(65 \cdot 7)$ & $116(92 \cdot 1)$ & $71(92 \cdot 2)$ & $22(100)$ & 232 \\
Yes (\%) & $12(34 \cdot 3)$ & $10(7 \cdot 9)$ & $6(7 \cdot 8)$ & $02(0)$ & 26 \\
Totals & 35 & 126 & 77 & 22 & 260 \\
\hline
\end{tabular}

Table 6 Comparison of other population based studies with the present study

\begin{tabular}{|c|c|c|c|c|}
\hline & English study" & New Zealand study $y^{\prime 3}$ & Danish study's & Present study \\
\hline $\begin{array}{l}\text { Number of children } \\
\text { Birth weight }(\mathrm{g}) \\
\% \text { of children }<1000 \mathrm{~g} \\
\text { ROP incidence }(\%) \\
\text { Severe ROP }(\%) \\
\text { Age at first examination } \\
\text { (weeks) }\end{array}$ & $\begin{array}{c}505 \\
\leq 1700 \\
13 \cdot 9 \\
49 \\
4 \cdot 2 \\
3\end{array}$ & $\begin{array}{c}313 \\
<1500 \\
26 \cdot 8 \\
21 \\
3 \cdot 8 \\
6-9\end{array}$ & $\begin{array}{c}201 \\
\leq 1750 \\
10 \\
28 \\
7 \\
4-5\end{array}$ & $\begin{array}{c}260 \\
\leq 1500 \\
28 \cdot 5 \\
40 \\
20 \\
4-6\end{array}$ \\
\hline $\begin{array}{l}\leq 2 \text { examinations }(\%) \\
\leq 5 \text { examinations }(\%) \\
\text { Dropouts }(\%)\end{array}$ & $\begin{array}{r}94 \cdot 3 \\
55 \cdot 2 \\
7.7\end{array}$ & $\begin{array}{l}28 \\
\mathrm{nc} \\
7 \cdot 2\end{array}$ & $\begin{array}{l}\mathrm{nc} \\
\mathrm{nc} \\
\mathrm{nc}\end{array}$ & $\begin{array}{l}94.6 \\
35 \\
11.9\end{array}$ \\
\hline
\end{tabular}

nc $=$ not calculated
Spontaneous regression of ROP was found in 50 of 83 eyes (right and left) with stage $1(60 \cdot 2 \%)$, in 52 of 112 eyes with stage $2(46.4 \%)$, and in 38 of 93 eyes with stage $3(40.9 \%)$. The rest of the eyes (right and left) in stage $3(n=55)$ progressed to a level where cryotherapy was indicated. This means that 77 of the 105 children with some stage of ROP had regression without any treatment (73.3\%).

Cryotherapy was performed in $28(10.8 \%)$ of the children at a mean postnatal age of 13.3 weeks (range 9-23 weeks) and a mean postmenstrual age of 40.4 weeks (range 36-48 weeks) respectively. Twenty seven of the children had symmetrical disease and both eyes were treated. Eight $(28.6 \%)$ of the 28 children had two treatments, three $(10.7 \%)$ were treated three times, and one (3.6\%) had four treatments. Twenty one $(75.0 \%)$ of the treated children had developed plus disease at the time of cryosurgery.

The cryosurgery was successful with regard to preventing the progression of the disease except in two children in whom vitreoretinal surgery was performed. In one child the disease, despite three cryotherapy treatments, had a malignant course and progressed to stage 4B with a low exudative detachment in the macular area, and required an operation with an encircling band. The other child, in whom the second examination had been delayed, developed stage 5 ROP and had major vitreoretinal surgery including lensectomy. Another five children progressed from stage 3 plus to mild $4 \mathrm{~A}$ during the delay between decision and performance of cryosurgery.

There was a significant correlation $(p=0.0001$, tested with $\chi^{2}$ analysis) between cryotherapy and low birth weight (Table 4) and early gestational age ( $p=0.0001$, tested with $\chi^{2}$ analysis) (Table 5 , Fig 6). There was no correlation between sex, single or multiple birth, and cryotherapy (tested with $\chi^{2}$ analysis).

\section{Discussion}

COMPARISON WITH PREVIOUS STUDIES

The present study showed that $40.4 \%$ of prematurely born children in the Stockholm county with a birth weight of $1500 \mathrm{~g}$ or less developed some degree of ROP. Since our study was population based it is not exactly comparable with the recent hospital based American multicentre study.$^{10}$ Of the four prospective population based studies ${ }^{1314}$ 15 (Table 6), the English one and ours are comparable in many aspects. The dropout frequency in the English study and in our study was $7 \cdot 7 \%$ and $11.9 \%$ respectively. The incidence of ROP was, however, slightly higher in the English study compared with ours, which may, apart from possible population differences on socioeconomic grounds, be explained by their earlier start and increased frequency of examinations and their rigorous use of speculum and scleral indentator. On the other hand the incidence of ROP of the English and the present study differ by being higher compared with the results of the New Zealand and Danish studies. With regard to the New Zealand study, this can be explained by the fact that $22 \%(68 / 313)$ of the children had their first examination postponed to 


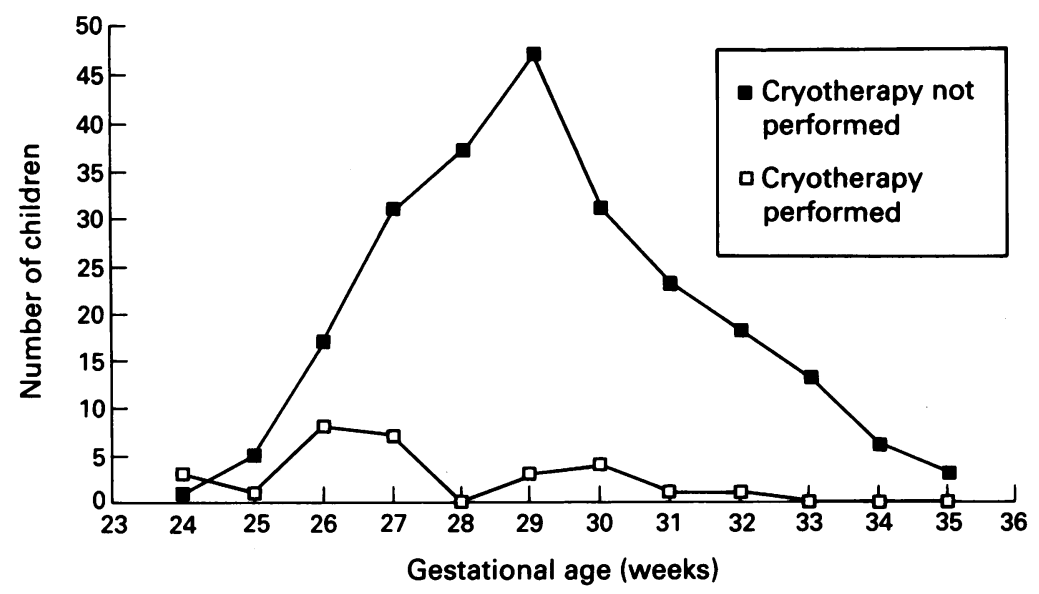

Figure 6 Number of children with and without cryotherapy at different weeks of gestation.

the $42 \mathrm{nd}$ week of gestation or later, and that $14 \%$ (44/313) were not followed for a sufficiently long time for complete vascularisation of the peripheral retina to occur. If our exclusion criteria had been applied, it would have resulted in a dropout of $40 \%$ instead of the reported $7 \%$. In the Danish study no details of the frequency of examinations or the number of dropouts were given.

Even if the total incidence of ROP differed in the different community based studies (Table 6), probably depending on differences of examination schedules and techniques, the incidence of severe ROP (stage 3 or more) was similar in all the three other studies (3-8-7\%) and considerably lower than we found. One reason for our higher incidence of severe ROP compared with the English study was probably that we had a higher frequency of smaller children (see Table 6). The English study also included children with a birth weight of up to $1700 \mathrm{~g}$ which may have contributed to their lower incidence of severe ROP in the total group. Furthermore, it must be mentioned that the incidence of severe ROP of $20.0 \%$ in our study is more compatible with the hospital-based American multicentre study, in which the incidence of severe ROP was $18 \cdot 3 \%{ }^{10}$ On the other hand the frequency of children with a birth weight up to $1000 \mathrm{~g}$ was higher $(54.6 \%)$ in the multicentre study than in the present study (28.5\%).

\section{SURVIVAL RATE AND INCIDENCE OF ROP}

The survival rate of neonates is another factor that might influence the incidence of ROP. A low survival rate of the most premature children would, for example, lead to a lower incidence of ROP, particularly severe ROP. There are, however, difficulties in comparing the survival rates of different studies since the definition of survival rate may differ. We found a survival rate for at least 8 weeks of $84 \%$ in our total group, and of $71 \%$ in children with a birth weight of $1000 \mathrm{~g}$ or less, while Fielder $e t a l^{22}$ presented the total number of live born infants in their study allowing a calculation of survival rate for 3 weeks of $71 \%$ among all children under $1500 \mathrm{~g}$ and of $51 \%$ among children under $1000 \mathrm{~g}$. For comparison, the survival rates at discharge for the two weight groups in the New Zealand study ${ }^{13}$ were $82 \%$ and $66 \%$, respectively, and the survival rates in the Danish study ${ }^{15}$ were $77 \%$ and
$58 \%$, respectively. Comparisons of survival rates and incidences of ROP with American studies are, however, difficult to undertake since the American studies either were not strictly population based or used a slightly different classification. ${ }^{23} 24$ One of these, however, had a survival rate of $73.6 \%$ for 28 days of neonates with a birth weight of up to $1250 \mathrm{~g}$ (the American multicentre study). ${ }^{23}$

In conclusion, the survival rate in our study appears higher than that of the English study, which, together with the fact that we had a higher proportion of children with a birth weight of less than $1000 \mathrm{~g}$, may explain the higher incidence of severe ROP in our study. The survival rate in the American multicentre study, although not population based, was relatively high, which may also explain their high frequency of severe ROP.

RELATION OF ROP AND ITS ONSET TO GESTATIONAL AGE AND BIRTH WEIGHT

We found a significant correlation of birth weight and gestational age to ROP. This was confirmed by logistic regression analysis in which both factors were found to be independent predictors for development of ROP. However, ROP was significantly more strongly associated with gestational age compared with birth weight.

Knowledge about the onset of ROP is of great importance when designing screening programmes. Already in 1952 an inverse correlation of birth weight and postnatal age at onset of retrolental fibroplasia was noted, although no significant correlation to gestational age was found ${ }^{25}$ and in a report to the British Medical Research Council $(1955)^{26}$ it was stated that retinopathy develops later in premature children with lower birth weight. Since the beginning of the 1980s the issue of onset of ROP has gained increasing attention. A clear correlation between birth weight and postnatal age at onset of ROP was reported by $\mathrm{Palmer}^{27}$ and Flynn $^{28}$. Fielder et $a l^{29}$ found gestational age as well as birth weight to show a significant negative correlation with postnatal age at onset. A fairly short range in time of the postmenstrual age at onset of ROP has been found..$^{1020}$ Two recent studies have shown a correlation of gestational and postmenstrual age at onset of ROP, indicating that perinatal events, apart from developmental events, may also influence the development of ROP..$^{30} 31$

In our study the mean postnatal age and the mean postmenstrual age at onset of ROP was $7 \cdot 9$ weeks (range 3-16) and 36 weeks (range 31-43) respectively. As 48 of the 260 children already had some degree of ROP at their first examination, these results may, however, be interpreted with caution. In the other population-based studies Fledelius ${ }^{15}$ noticed similar mean times of onset of ROP, while Fielder $e t \mathrm{al}^{30}$ found that the postnatal age at onset of ROP was inversely proportional to both decreasing birth weight and gestational age. The postmenstrual age at onset varied between 29.7 to 45.0 weeks with $80.8 \%$ appearing between 30.0 and 37.8 weeks. ${ }^{30}$ Regarding onset of the different stages (1 to 3) their results were compatible with ours. Finally, 
we can confirm the recently noted tendency ${ }^{3031}$ that ROP onset in neonates with lower gestational age is earlier than in those with a high gestational age (see Fig 5).

\section{INDICATIONS AND RESULTS OF CRYOTHERAPY}

Cryotherapy was performed in $10 \cdot 8 \%$ (28/260) of the children in our study. The lower age limit of children requiring cryotherapy was 36 weeks of postmenstrual age and 9 weeks of postnatal age. Most of the children were treated when the disease had just reached the threshold according to our definition. Results of frequency of cryotherapy may be difficult to compare with other studies if they are based on selected materials ${ }^{62132}$ or if the indications for cryotherapy vary. Compared with our study, the American multicentre trial of cryotherapy for $\mathrm{ROP}^{21}$ reported a lower incidence $(6 \%)$ of 'threshold' disease among their children with a birth weight of $1250 \mathrm{~g}$ or less. They performed cryotherapy slightly later than we did and defined threshold disease as stage $3+$ ROP in five or more contiguous or eight cumulative clock hours $\left(30^{\circ}\right.$ sectors) of either zone 1 or 2 . Nissenkorn et $a l^{32}$ reported a higher frequency $(35 \cdot 3 \%)$ of cryotherapy in their selected study of neonates with a birth weight of $1250 \mathrm{~g}$ or less. They performed cryosurgery when confluent fibrovascular proliferations in stage 3 occupied more than three clock hours in zone 1 or 2 with plus disease. Thus, the incidence and need for cryotherapy has to be evaluated further, particularly in relation to the degree and extent of ROP and to subsequent visual function and refractive error. We plan to follow the children in our study for at least $3 \cdot 5-4$ years.

\section{SCREENING FOR ROP}

Since the beginning of the 1980s designs of screening programmes to identify children with ROP stage 3 who require cryotherapy have been a subject of interest for several groups and so many differing guidelines have emerged. Palmer $^{27}$ and Flynn ${ }^{28}$ proposed examination between 7 and 9 weeks and between 8 and 10 weeks respectively, provided only one single examination is performed. Brown et al ${ }^{33}$ suggested inclusion of children with a birth weight of $1600 \mathrm{~g}$ or less and Tan and Cats ${ }^{34}$ suggested examinations to be performed at $5,8,11$, and 14 17 weeks of age. Darlow ${ }^{13}$ preferred inclusion of children with a gestational age of 30 weeks or less and with a birth weight of $1250 \mathrm{~g}$ or less, while Fledelius $^{35}$ suggested $\leq 32$ weeks and a birth weight below $1750 \mathrm{~g}$. During the past few years many authors have emphasised the importance of onset of ROP in designing a screening schedule. ${ }^{27} 3031$ 35-37 This fact was taken into account when guidelines for ROP screening in the United Kingdom recently were drawn up suggesting that neonates with a birth weight of less than $1500 \mathrm{~g}$ and a gestational age of 31 weeks or less are given a first examination at 7 weeks of postnatal age. ${ }^{38}$

In designing a general screening programme one has to be aware of the danger of basing guidelines on one single study, particularly if the cohort is not very large, and of the risk of giving recommendations based on a study covering one particular area of a specific country. Still we would like to make some comments on the design of a screening programme deriving from the results of our study. We suggest that inclusion of children in a schedule could be done from gestational age only, at least in Sweden where ultrasonography is routinely performed in the first stage of pregnancy. This statement is based on the fact that we found a correlation of low birth weight and early gestational age with severe ROP, gestational age showing the most significant association, which confirms the idea that the degree of immaturity is a main predictive factor for ROP. Our findings, furthermore, indicate a borderline between 32 and 33 weeks of gestation, since no child with a gestational age of more than 32 weeks ever developed severe ROP or was submitted to cryotherapy. We therefore suggest the inclusion of children with a gestational age of 32 weeks or less in a screening programme, at least in our area.

As far as the timing of the first examination is concerned, the analysis of the onset of the disease and its different stages is very important. Based on our results there should be almost no risk of developing ROP stage 3 before 32 weeks of postmenstrual age and no need for cryosurgery before a postmenstrual age of 36 weeks. However, such limits cannot be applied too strictly, since there was a significant correlation between gestational age and ROP onset time at postmenstrual age (see Fig 5B), which means that the smaller neonates develop ROP earlier than more mature ones. It also indicates that there may be other factors than strictly developmental ones such as birth and postnatal factors, that are responsible for the ROP disease. Another reason for not rigorously following the postmenstrual age limit of 32 weeks is the risk of 'rush disease'. Bearing these factors in mind, we suggest the safest and most practical way is to make the first examination at a postnatal age of 5-6 weeks when the few children who may develop 'rush disease' may also be identified.

We would like to thank Dr Daniela Sachs and Dr Jaan Sule for valuable assistance with fundus examinations. We would also like to thank Dr Greger Lindberg, Huddinge University Hospital, for statistical and computer advice, and Maria Blomster-Krüger for assistance in data input. The study was supported by Carmen and assistance in data input. The study was supported by Carmen and Bertil Regnérs fond, Kronprinsessan Margaretas Arbetsnämnd
för synskadade, Stiftelsen Samariten, Stiftelsen Frimurarna för synskadade, Stiftelsen Samariten, Stiftelsen Frimurarna Barnhuset i Stockholm, Medical Research Council (grant no
4751), Karolinska institutes fonder, and Sigvard and Marianne Bernadotte Research Foundation for Children Eye Care.

1 Phelps DL. Retinopathy of prematurity: an estimate of vision loss in the United States - 1979. Pediatrics 1981; 67: 924-6. Kingham JD. Acute retrolental fibroplasia. Arch Ophthalmol 1977; 95: 39-47.

3 Kalina RE, Karr DJ. Retrolental fibroplasia: experience over two decades in one institution. Ophthalmology 1982; 89: 91-

4 Keith CG, Kitchen WH. Ocular morbidity in infants of very low birth weight. Br F Ophthalmol 1983; 67: 302-5.

5 Tasman $W$. The natural history of active retinopathy of prematurity. Ophthalmology 1984; 91: 1499-1503.

6 Reisner SH, Amir J, Shohat M, Krikler R, Nissenkorn I, BenSira I. Retinopathy of prematurity: incidence and treatment. Arch Dis Child 1985; 60: 698-701.

7 Flynn JT, Bancalari E, Bachyansky BN, Buckley EB, Bawol $\mathrm{R}$, Goldberg R, et al. Retinopathy of prematurity. Diagnosis, severity and natural history. Ophthalmology 1987;94:620-9.

8 Schulenberg WE, Prendville A, Ohri R. Natural history of retinopathy of prematurity. BrF Ophthalmol 1987; 71: 83743. 
9 Nissenkorn I, Ben Sira I, Kremer I, Gaton DD, Krikler R, Wielunsky E, et al. Eleven years' experience with retinopathy of prematurity: visual results and contribution of cryoablation. Br f Ophthalmol 1991; 75: 158-9.

10 Palmer EA, Flynn JT, Hardy RJ, Phelps DL, Phillips CL, Schaffer DB, et al. Incidence and early course of retinopathy of prematurity. Ophthalmology 1991; 98: 1628-40.

11 Committee for the Classification of Retinopathy of Prematurity. An international classification of retinopathy of prematurity. Arch Ophthalmol 1984; 102: 1130-4

12 International Committee for the Classification of the Late Stages of Retinopathy of Prematurity. An international classification of retinopathy of prematurity. Arch Ophthalmol 1987; 105: 905-12.

13 Darlow BA. Incidence of retinopathy of prematurity in New Zealand. Arch Dis Child 1988; 63: $1083-6$.

$14 \mathrm{Ng} \mathrm{YK}$, Fielder AR, Shaw DE, Levene MI. Epidemiology of retinopathy of prematurity. Lancet 1988; ii: 1235-8.

15 Fledelius HC. Retinopathy of prematurity. Clinical findings in a Danish County 1982-87. Acta Ophthalmol 1990; 68: 209a Dan.

16 Saigal S, Rosenbaum P, Stoskopf B, Milner R. Follow-up of infants $501-1500 \mathrm{~g}$ birth weight delivered to residents of a geographically defined region with perinatal intensive caring geographically defined region with perina

17 Saigal S, Rosenbaum P, Stoskopf B, Sinclair JC. Outcome of infants $501-1000 \mathrm{~g}$ birth weight delivered to residents of the McMaster Health Region. F Pediatr 1984; 105: 969-76.

18 Fledelius HC. Prematurity and the eye. Copenhagen, Denmark: JJ Trykteknik, 1976.

19 Gallo JE, Lennerstrand G. A population-based study of ocular abnormalities in premature children aged 5 to 10 years. $A m \mathcal{F}$ Ophthalmol 1991; 111: 539-47.

20 Gallo JE, Holmström GE, Kugelberg U, Hedquist B, Lennerstrand G. Regressed retinopathy of prematurity and its sequelae in children aged 5-10 years. Br $\mathcal{F}$ Ophthalmol 1991; 75: 527-31.

21 Cryotherapy for Retinopathy of Prematurity Cooperative Group. Multicenter trial of cryotherapy for retinopathy of Group. Multicenter trial of cryotherapy for retinopat
prematurity. Arch Ophthalmol 1990; 108: 1408-16.

22 Fielder AR, Shaw DE, Ng YK. Retinopathy of prematurity. [Letter] Lancet 1989; i: 275-6.

23 Phelps DL, Brown DR, Tung B, Cassady G, McClead RE, Purohit DM, et al. 28-Day survival rates of 6676 neonates with birth weights of $1250 \mathrm{~g}$ or less. Pediatrics $1991 ; 87: 7-$ 17.
24 Johnson LH, Quinn GE, Abbasi S, Bowen FW. Retinopathy of prematurity: prevalence and treatment over a 20 year period at Pennsylvania Hospital. Doc Ophthalmol 1990; 74: 213-22.

25 Silverman WA, Blodi FC, Locke JC, Day RL, Reese AB. Incidence of retrolental fibroplasia in a New York nursery. Arch Ophthalmol 1952; 48: 698-711.

26 Report to the Medical Research Council by their council on retrolental fibroplasia. Retrolental fibroplasia in the United retrolental fibroplasia. Retrolen

27 Palmer EA. Optimal timing of examination for acute retrolental fibroplasia. Ophthalmology 1981; 88: 662-6.

28 Flynn JT. 'Optimal timing of examination for acute retrolental fibroplasia'. [Discussion.] Ophthalmology 1981; 88: 667-8.

29 Fielder AR, Ng YK, Levene MI. Retinopathy of prematurity: age at onset. Arch Dis Child 1986; 61: 774-8.

30 Fielder AR, Shaw DE, Robinson J, Ng YK. Natural history of retinopathy of prematurity: a prospective study. Eye 1992; 6: 233-42.

31 Quinn GE, Johnson L, Abbasi S. Onset of retinopathy of prematurity as related to postnatal and postconceptional age. prf Ophthalmol 1992; 76: 284-8.

32 Nissenkorn I, Axer-Siegel R, Kremer I, Ben-Sira I. Effect of partial cryoablation on retinopathy of prematurity. $B r \mathcal{F}$ Ophthalmol 1991, 75: 160-2.

33 Brown DR, Biglan AW, Stretavsky MA. Screening criteria for the detection of retinopathy of prematurity in patients in a neonatal intensive care unit. $\mathcal{F}$ Pediatr Ophthalmol Strabismus $1987 ; 24: 212-4$

34 Tan KE, Cats BP. Timely incidence of retinopathy of prematurity and its consequences for the screening strategy. Am ₹ Perinatol 1989; 6: 337-40.

35 Fledelius HC, Rosenberg T. Retinopathy of prematurity. Where to set screening limits? Recommendations based on two Danish surveys. Acta Paediatr Scand 1990; 79: 906-10.

36 Acheson JF, Schulenberg WE. Surveillance for retinopathy of prematurity in practice: experience from one neonatal prematurity in practice: experience
intensive care unit. Eye 1991; 5: 80-5.

37 Fielder AR, Levene MI. Screening for retinopathy of prematurity. Arch Dis Child 1992; 67: 860-7.

38 ROP screening duty. College News. $Q$ Bull Coll Ophthalmologists 1990 (autumn).

39 Nissenkorn I, Kremer I, Gilad E, Cohen S, Ben-Sira I. 'Rush' type retinopathy of prematurity: report of three cases. $\mathrm{Br} \mathcal{F}$ Ophthalmol 1987; 71: 559-62.
Op 